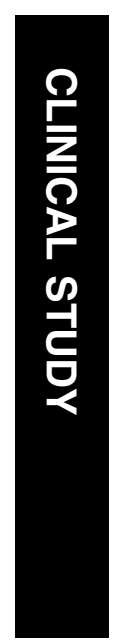

\title{
Cross-infection risk of felt-tipped marker pens in cataract surgery
}

\begin{abstract}
Purpose To assess the potential of bacterial transmission using felt-tipped marker pens on forehead skin before cataract surgery. Methods A total of 64 marker pens taken from clinical stock were tested. Forty-eight new pens were cultured in the laboratory. They were first left to desiccate

for 0,4 , and $16 \mathrm{~h}$, then dipped into solutions of 0.5 Macfarlane's concentration of coagulase negative staphylococci (CNS), methicillin-resistant Staphylococcus aureus (MRSA) and coliforms, and transferred onto the culture medium after 5, 10, 30, and $120 \mathrm{~min}$ intervals of exposure to air. A further 16 pens were collected after routine clinical use for 5 working days and cultured.
\end{abstract}

${ }^{1}$ Moorfields Eye Hospital, London, UK

\section{${ }^{2}$ Department of} Microbiology, St George's Hospital, London, UK

${ }^{3}$ Department of Ophthalmology, Great Ormond Street Hospital for Children, London, UK

${ }^{4}$ Moorfields Eye Hospital at St George's, London, UK

Correspondence: DA Sim, Moorfields Eye Hospital, 162 City Road, London EC1V 2PD, UK

Tel: 208725 2064/79 840 17957;

Fax: 2087250372.

E-mail: dawnsim@

doctors.org.uk

Received: 18 March 2008 Accepted in revised form: 1 June 2008

Published online: 11 July 2008

This research was presented as a Poster in the American Academy of Ophthalmology Annual Meeting 2007,

New Orleans

The authors have no

financial interest or affiliations with this research
Results Positive cultures were observed in $100 \%$ of pens at $0 \mathrm{~min}$, and $44.4 \%$ at $5 \mathrm{~min}$ after the organism was exposed to air. Escherichia coli showed least transmissibility with no growth in all plates after $5 \mathrm{~min}$ of exposure. Only MRSA showed heavy growth after 10 min of exposure. No pattern emerged with reference to the length of time; each pen was left to desiccate. No growth was observed in the cultures of all 16 marking pens after clinical use.

Conclusions The potential for transmission of bacteria through felt-tipped marker pens has not been explored in cataract surgery. This study demonstrated that a theoretical risk of transmission exists in a laboratory setting, and survival times of the bacteria decreased with time. This suggests that the interval in which patients are marked with the same pen may play a role in bacterial transmission.

Eye (2009) 23, 1094-1097; doi:10.1038/eye.2008.214; published online 11 July 2008

Keywords: infection; marker; opthalmology; pen; surgery
DA Sim¹, N Feasey², S Wren ${ }^{3}$, A Breathnach ${ }^{2}$ and $\mathrm{G}$ Thompson ${ }^{4}$

\section{Introduction}

Wrong-site surgery has been a popular topic of discussion in the mainstream press in the past decade. Although its occurrence is relatively rare, the consequences can be disastrous. As wrong-site surgery is an error that is entirely preventable, and several organizations and governing bodies have advocated marking of the surgical site. ${ }^{1-4}$ This has been used routinely in many ophthalmic units performing a high volume of cataract surgery to reduce the unnecessary risk of wrong-site operations.

Felt-tipped marker pens are used to mark a serial number of patients before surgery, often within a short space of time. The potential for bacterial transmission through felt-tipped marking pens used in surgical site marking on forehead skin before cataract surgery has not been explored.

Nosocomial infections have been a major concern and are associated with important consequences. Putative sources of hospital infections have been investigated intensively over the recent years. Doctor's writing tools, ${ }^{2}$ stethoscopes, ${ }^{3}$ and inefficient handwashing procedures, ${ }^{4}$ have all been shown to be sources of infection transmission.

In this study, we access the potential of surgical site marker pens as a source of nosocomial infection, and address the following questions: (1) the transmissibility of different types of bacteria, (2) survival times of bacteria on marker pen tips after exposure to air, and (3) transmission risks with fresh $v$ s desiccated pens.

\section{Materials and methods}

We conducted this study in two phases; the first with new pens and second with pens in routine clinical use. A total of 64 marker pens taken from clinical stock were tested.

In the first phase, 48 brand new felt-tipped marker pens (Dry Wipe, Banner) were divided 
into three groups of 10 , and left to desiccate for 0,4 , and $16 \mathrm{~h}$ to emulate new and older dried-out pens (Figure 1). Three pens, one from each group, was used as controls and cultured after being dipped in distilled water. The three groups of marker pens were further divided to test three different organisms: coagulase negative staphylococci (CNS) $(n=15)$, methicillin-resistant Staphylococcus aureus (MRSA) $(n=15)$, and coliforms (Escherichia Coli) $(n=15)$. Marker tips were dipped into solutions of $0.5 \%$ Macfarlane's concentration for each test organism and transferred onto the culture medium. In all subgroups $(n=5)$ (Figure 1), each pen tip was exposed to air for either, $0,5,10,30$, or $120 \mathrm{~min}$ before plating.

In the second phase, a total of 16 pens were collected after each pen was used for 5 working days; 10 full operating lists; with each pen marking 10-16 patients per day. Pen tips were plated under standard conditions for $48 \mathrm{~h}$.

Culture medium and incubation used for both phases were, Columbia blood agar in carbon dioxide at $37^{\circ} \mathrm{C}$, and CLED in air at $37^{\circ} \mathrm{C}$.

\section{Results}

\section{Phase 1}

Transmission risks with different types of bacteria E. coli showed least transmissibility with no growth in all plates after $5 \mathrm{~min}$ of exposure. CNS showed minimal growth $(+)$ in all pens after $5 \mathrm{~min}$, and scanty growth after 10 min of exposure (Figure 2). MRSA showed the highest level of transmissibility with heavy growth $(+++)$ in $33.3 \%$ of pens at $5 \mathrm{~min}$ and heavy growth after $10 \mathrm{~min}$ of exposure (Figure 2), as the only bacteria that showed any growth at $10 \mathrm{~min}$.
Survival times of bacteria on marker pen tips after exposure to air

Positive cultures were observed in 100, 44.4, and $33.3 \%$ of pens at 0,5 , and $10 \mathrm{~min}$ after the organism was exposed to air. There was no growth on any plates after $30 \mathrm{~min}$ of exposure (Figure 2).

Fresh vs desiccated pens

No pattern emerged with reference to the length of time; each pen was left to desiccate (Figures 2 and 3).

\section{Control pens}

There was no growth from control pens (Figure 1).

\section{Phase 2}

There was no growth in the cultures of all 16 marker pens after routine clinical use for 5 working days.

\section{Discussion}

Numerous studies have explored the potential risk of skin bacteria among patients with the use of a marker pen. ${ }^{5-10}$ Results from these studies are conflicting, with both subject (type of pen) and methodology varying widely among studies. However, amongthese studies, alcohol-impregnated pens seems to be less likely to transmit bacteria than older, dried-out pens. ${ }^{5,6}$ A few studies failed to demonstrate any transmission, ${ }^{7,8}$ and no study has cultured bacteria from pens collected in clinical areas.

This exploratory study was designed to investigate Dry Wipe markers, which are non-alcohol-impregnated, and widely used in our trust, particularly in a high volume of cataract surgery. In the first experiment, its

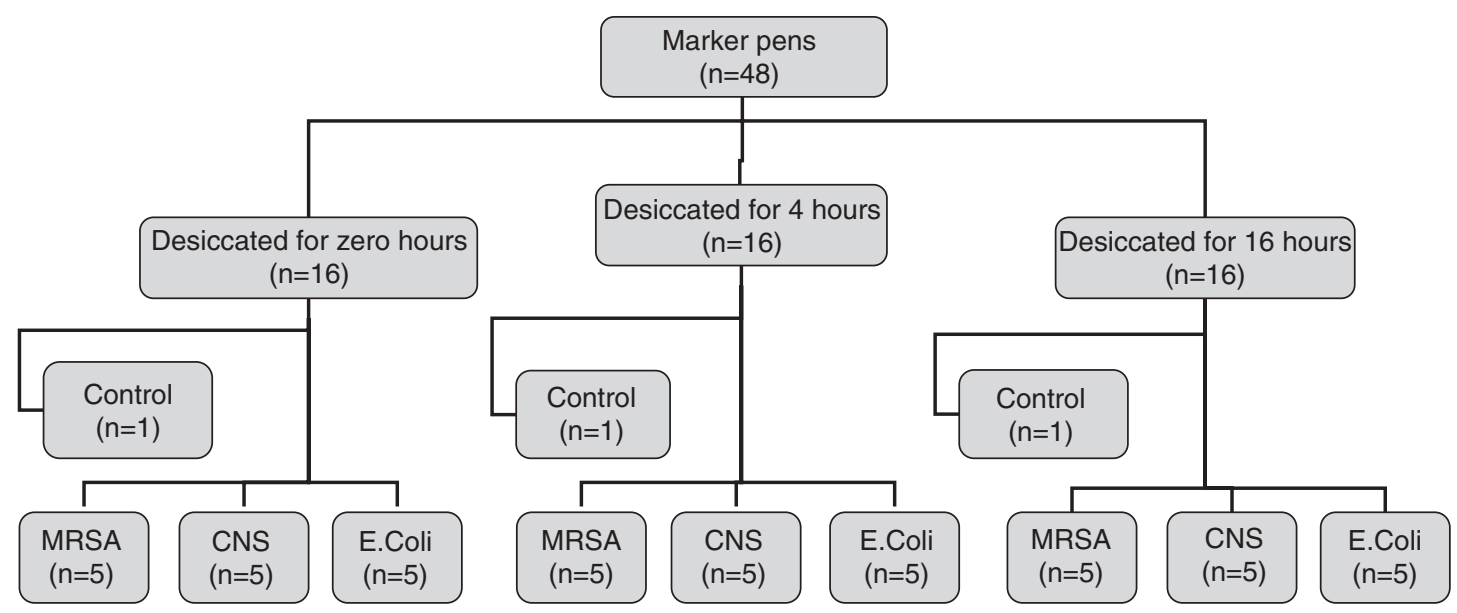

Figure 1 Allocation of marker pens for testing in phase 1. $\mathrm{N}=$ number of marker pens, MRSA = methicillin-resistant Staphylococcus aureus, $\mathrm{CNS}=$ coagulase negative staphylococci, E.Coli= coliforms. 


\begin{tabular}{|c|c|c|c|c|c|c|}
\hline & $\begin{array}{c}\text { Time of } \\
\text { exposure (min) }\end{array}$ & 0 & 5 & 10 & 30 & 120 \\
\hline $\begin{array}{c}\text { Time left to } \\
\text { dessicate (Hours) }\end{array}$ & \multicolumn{6}{|l|}{ MRSA } \\
\hline 0 & & +++ & $N G$ & +++ & $N G$ & $N G$ \\
\hline 4 & & +++ & $N G$ & $N G$ & $N G$ & $\mathrm{NG}$ \\
\hline \multirow[t]{2}{*}{16} & & +++ & +++ & $N G$ & NG & $\mathrm{NG}$ \\
\hline & \multicolumn{6}{|l|}{ CNS } \\
\hline 0 & & +++ & + & Scanty & $\mathrm{NG}$ & $\mathrm{NG}$ \\
\hline 4 & & +++ & + & Scanty & NG & $\mathrm{NG}$ \\
\hline \multirow[t]{2}{*}{16} & & +++ & + & $N G$ & $N G$ & $\mathrm{NG}$ \\
\hline & \multicolumn{6}{|l|}{ E.coli } \\
\hline 0 & & +++ & $N G$ & $N G$ & $N G$ & $N G$ \\
\hline 4 & & +++ & $N G$ & NG & NG & $N G$ \\
\hline 16 & & +++ & $N G$ & $N G$ & $N G$ & $\mathrm{NG}$ \\
\hline
\end{tabular}

Figure 2 Table summary of results. NG $=$ no growth, and,,++++++ and scanty are typical microbiology descriptions for heaviness of growth on purity plates (refer to Figure 3).

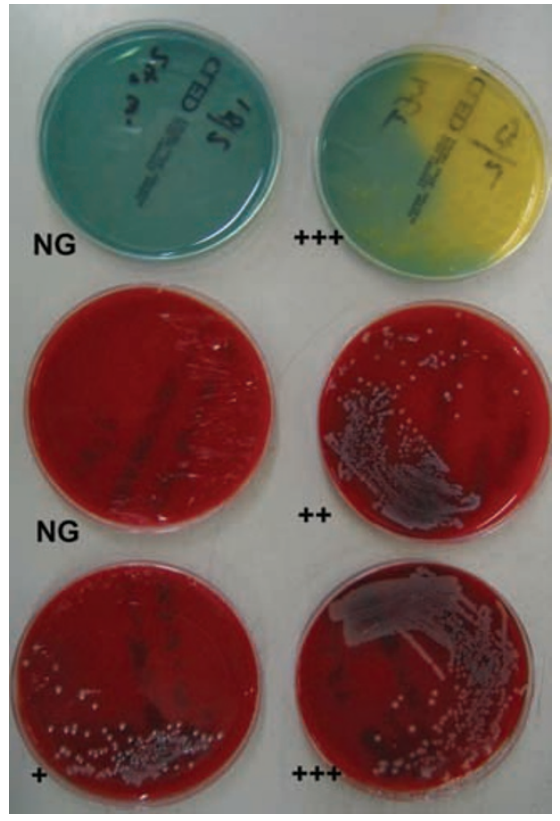

Figure 3 Cled and blood agar plates illustrating different intensities of bacterial growth. $\mathrm{NG}=$ no growth, and,+++ , +++ and scanty are typical microbiology descriptions for heaviness of growth on purity plates.

methodology was designed to emulate surgical practice in our unit. The pens were desiccated for the specified periods of time to represent new and older dried-out pens. Time intervals between exposure to air (ie uncapping a pen), and inoculation of bacteria, were chosen to emulate the short periods of intervals in which patients are seen and marked before a surgical list. The three test bacteria were chosen for the following reasons: CNS, a common skin commensal, is the most common causative organism in bacterial endophthalmitis. ${ }^{11}$

E. Coli, representing Gram-negative organisms associated with inefficient handwashing, and MRSA, though rare in bacterial endophthalmitis, a favourite with the popular press.

These chosen bacteria showed variability in their transmissibility, and were observed to be highest in MRSA. Survival times of the bacteria on marker pens decreased with time, suggesting that the interval in which patients are marked with the same pen, may play a role in bacterial transmission. Unlike earlier studies, we did not demonstrate greater transmissibility with desiccated $v s$ fresh pens. Although a theoretical risk has been shown in the laboratory, the difficulty lies in the quantification and clinical application of this risk. Negative cultures were obtained on all pens used in clinical practice, suggesting that this risk may be very small, and bring into question its role in the prevention of endophthalmitis.

The best available evidence for increased endophthalmitis risks include the following: patients who are aged above 80 years, the use of preoperative povidone iodine $^{12}$ in the eye before surgery, using intracameral cefuroxime when the operation is completed, ${ }^{13}$ placing the main incision on the sclera rather than on clear corneal, ${ }^{14}$ and the lack of intraoperative complications. ${ }^{9}$ Interpreting evidence 
regarding the prevention of endophthalmitis after cataract surgery is fraught with difficulty. ${ }^{15}$ There are numerous methodological hurdles because of the relative rarity of the condition and the multiple approaches of surgeons to preoperative measures of prevention. ${ }^{15}$ Some of these practices are not based on evidence, yet are carried out with rigorous fervour. This results in numerous variables that need to be measured in studies assessing endophthalmitis risk. Interpreting and applying evidence regarding postoperative endophthalmitis rates in cataract must therefore be integrated individual clinical expertise. ${ }^{16}$

Further research is required to clarify the role of marker pens in transmission of bacteria. We feel that the risks of wrong-site surgery should always be balanced against transmission risk and our findings do not sanction withdrawal of surgical site marking. The use of disposable marking pens at a cost of approximately $£ 0.70$ per pen represents a substantial sum to the trust in a high volume of cataract surgery. There is no evidence currently that supports implementing this. However, simple measures, such as increasing the intervals between marking patients with the same pen, not marking close to the surgical field, and wiping away the site mark during sterile surgical preparations can, and have already been employed in clinical practice. Further caution can be exercised by using disposable pens when marking MRSA patients, particularly with at risk individuals, such as the elderly or immunocompromised.

\section{References}

1 Traquair H. Removal of the wrong eye. Br J Ophthalmol 1947; 31: 8-12.

2 Datz C, Jungwirth A, Dusch H, Galvan G, Weiger T. What's on doctor's ball point pens? Lancet 1997; 350(9094): 1824.

3 Marinella MA, Pierson C, Chenoweth C. The stethoscope: a potential source of nosocomial infection? Arch Intern Med 1997; 157: 786-790.
4 Steere AC, Mallison GF. Handwashing practices for the prevention of nosocomial infections. Ann Intern Med 1975; 83: 683-690.

5 Tadiparthi S, Shokrollahi K, Juma A, Croall J. Using marker pens on patients: a potential source of cross infection with MRSA. Ann R Coll Surg Engl 2007; 89(7): 661-664.

6 Thomas RJ, Goodbourne C, Goldie B. The transmission of MRSA via orthopaedic marking pens - fact or fiction. Annals of the Royal College of Surgeons of England 2004; 86: 51-52.

7 Russell PG, McKinnell TH. Cross infection risk in surgical marking pens. J Plast Reconstr Aesthet Surg 2007; 60(5): 572-573; e-pub 2007 Jan 31.

8 Cronen G, Ringus V, Sigle G, Ryu J. Sterility of surgical site marking. Journal of Bone E Joint Surgery - American Volume 2005; 87: 2193-2195.

9 Wilson J, Tate D. Can preoperative skin marking transfer methicillin-resistant Staphylococcus aureus between patients? A laboratory experiment. J Bone Joint Surg Br 2006; 88(4): 541-542.

10 Tenenhaus M, Bhavsar D. Do marking inks pose an infection risk? A surgeon's perspective. Surg Infect (Larchmt) 2006; 7(5): 481-483.

11 Lalwani GA, Flynn Jr HW, Scott IU, Quinn CM, Berrocal $\mathrm{AM}$, Davis JL et al. Acute-onset endophthalmitis after clear corneal cataract surgery (1996-2005). Clinical features, causative organisms, and visual acuity outcomes. Ophthalmology 2008; 115(3): 473-476; e-pub 2007 Dec 11.

12 Speaker MG, Menikoff JA. Prophylaxis of endophthalmitis with topical povidone iodine. Ophthalmology 1991; 98: 1769-1775.

13 Barry P, Seal DV, Gettinby G, Lees F, Peterson M, Revie CW, ESCRS Endophthalmitis Study Group. ESCRS study of prophylaxis of postoperative endophthalmitis after cataract surgery: preliminary report of principal results from a European multicenter study. J Cataract Refract Surg 2006; 32: 407-410.

14 Lundström M, Wejde G, Stenevi U, Thorburn W, Montan P. Endophthalmitis after cataract surgery. A nationwide prospective study-evaluating incidence in relation to incision type and location. Ophthalmology 2007; 114: 866-870.

15 Schein OD. Prevention of endophthalmitis after cataract surgery: making the most of the evidence. Ophthalmology 2007; 114: 831-832.

16 Sackett DL, Rosenberg WM, Gray JA, Haynes RB, Richardson WS. Evidence based medicine: what it is and what it isn't. BMJ 1996; 312: 71-72. 